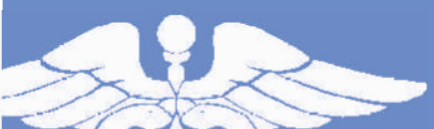

ISSN: 2782-7550 (Print) ISSN: 2782-7542 (Online)
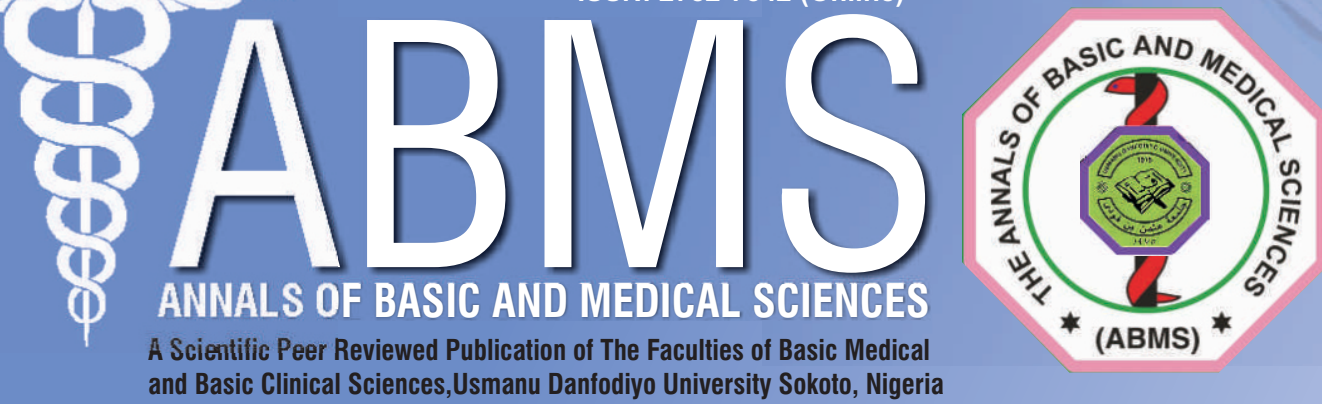

and Basic Clinical Sciences,Usmanu Danfodiyo University Sokoto, Nigeria
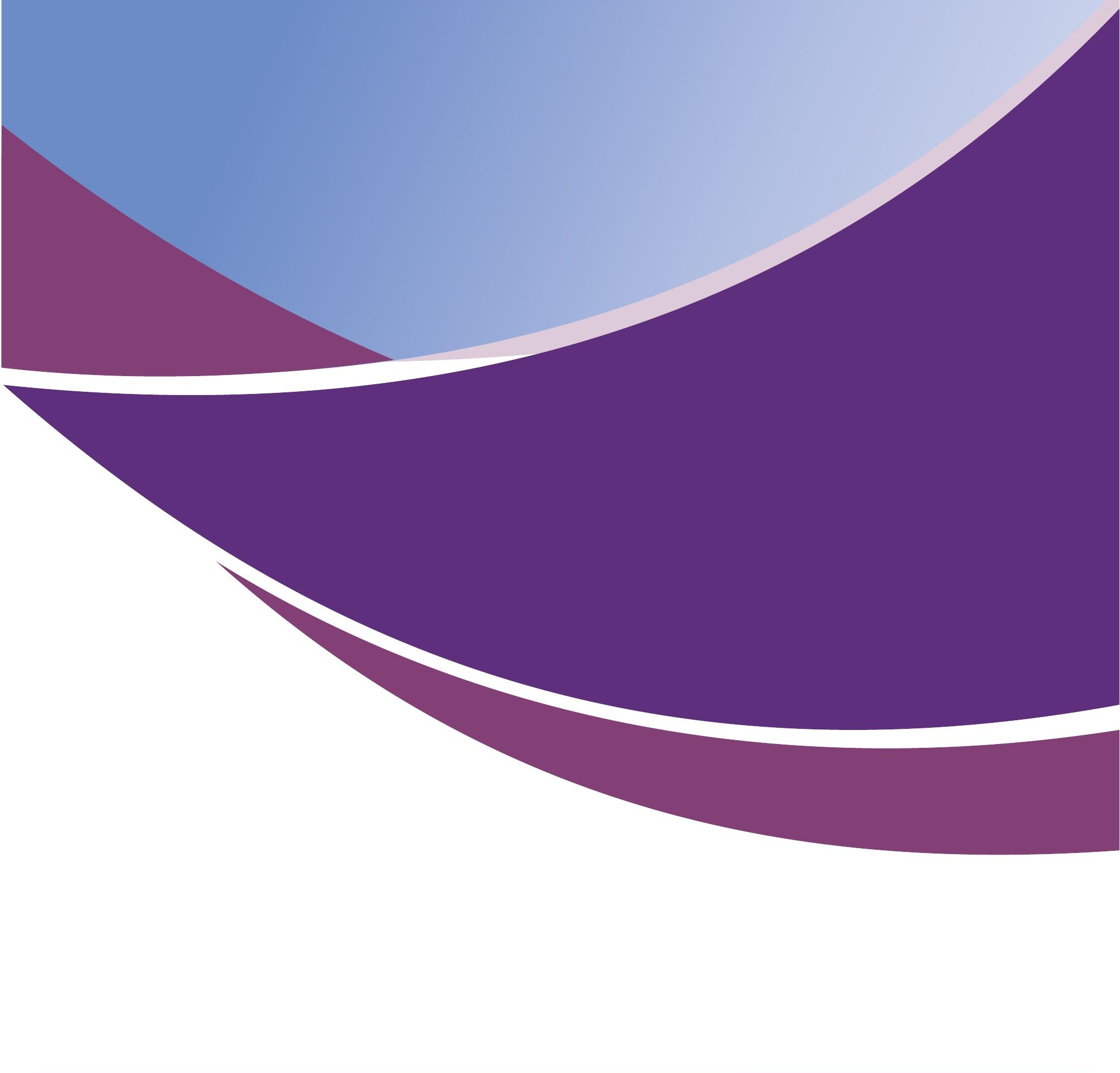


\section{Formulation and Nutritional Evaluation of a Nutraceutical with Antioxidant Activity Developed for the Management of Metabolic Syndrome}

Sumayya Ahmed Ayuba ${ }^{1}$, Farida Bashar ${ }^{2}$, Abdulkarim Yusuf ${ }^{2}$, Andrew Onu², Suleiman Alhaji Muhammad ${ }^{2}$, Yusuf Saidu ${ }^{2}$, Lawal Suleiman Bilbis ${ }^{2}$ and Abdullahi Yahya Abbas ${ }^{2}$.

${ }^{1}$ Department of Biochemistry, Faculty of Science, Sokoto State University, Sokoto, Nigeria

${ }^{2}$ Department of Biochemistry, Faculty of Science, Usmanu Danfodiyo University Sokoto, Nigeria

\section{Abstract}

Background: Antioxidants are critical for maintaining optimum health and wellbeing and they protect the body against the development of diseases caused by oxidative stress. Nutraceuticals are foods or part of food that have medical benefit. The present study formulated and nutritionally evaluated an antioxidant rich nutraceutical.

Materials/Methods: Nutritional analysis of proximate composition, amino acids and fatty acids profile, antioxidants vitamins and minerals were determined using standard methods. Tomatoes, ginger, garlic, onion, watermelon seed, lemon juice and palm oil were used to formulate the nutraceutical.

Results: Proximate composition analysis revealed that the nutraceutical is rich in ash $(3.00 \pm 0.001 \%)$, protein $(22.09 \pm 0.01 \%)$ and Lipid $(30.00 \pm 0.06 \%)$. The nutraceutical was also found to be low in moisture $(4.00 \pm 0.02 \%)$ and Carbohydrate $(38.78 \pm 0.05 \%)$ contents. Vitamins A, C and E concentrations obtained were $12.7 \pm 3.7 \mathrm{mg} /$ $100 \mathrm{~g}, 8.2 \pm 0.04 \mathrm{mg} / 100 \mathrm{~g}$, and $5.5 \pm 0.04 \mathrm{mg} / 100 \mathrm{~g}$ respectively. Concentration of the antioxidant minerals were Mn (590.2 $\pm 4.4 \mathrm{mg} / 100 \mathrm{~g}), \mathrm{Cr}(212.2 \pm 16.6 \mathrm{mg} / 100 \mathrm{~g}), \mathrm{Cu}(53.1 \pm 7.3 \mathrm{mg} / 100 \mathrm{~g})$ and $\mathrm{Zn}(5.3 \pm 0.2 \mathrm{mg} / 100 \mathrm{~g})$. Both essential and non-essential amino acids were detected in the formulated nutraceutical with arginine and leucine having the highest concentration among the essential amino acids while glutamate and asparagine constitute the highest concentration among the non-essential amino acids. The fatty acids analysis revealed the presence of high amount of oleic and lauric acids.

Conclusion: The formulated nutraceutical can serve as a suitable source of amino acids, antioxidant vitamins and minerals hence might have potentials in the management of diseases related to oxidative stress.

Key words: Nutraceutical, Antioxidants, Oxidative stress, Amino acids.

Corresponding author: Abdullahi Yahya Abbas Department of Biochemistry, Faculty of Science, Usmanu Danfodiyo University, Sokoto, Nigeria Email: ayabbas2002@yahoo.com Tel: 08035052927
Introduction

A ntioxidants are critical for maintaining optimum health and well being and they protect the body against the development of diseases caused by oxidative stress(1). Oxidative stress has been implicated in the progression of major health problems by inactivating the metabolic enzymes and damaging important cellular components, oxidizing the nucleic acids, leading to human ageing and diseases $(2,3)$ such as cardiovascular diseases (CVDs) $(4,5,6)$, diabetes (7), obesity (8), neurological diseases, cancer and blood disorders among others (9). Oxidative stress occurs from the imbalance between reactive oxygen and nitrogen species (RONS) production and antioxidant defenses. Miyajima et al., (10) indicated the role of oxidative stress in the pathogenesis of hypertension. Fermented papaya preparation, obtained from fermentation of Carica papaya Linn using yeast was considered a food supplement that exhibits antiinflammatory, antioxidant, and immunostimulatory functions that may positively affect the clinical damage induced by oxidative stress (11). Firuzi et al., (12) conducted a study on the effect of intake of different vitamins and on the risk of CVDs, suggesting that higher intake of these vitamins significantly lowered the risk of these pathologic conditions. Given the reported inverse relationship between the dietary intake of antioxidantrich food and the incidence of human diseases, there has been a global trend toward increasing the intake of natural antioxidants, especially in the geriatric population $(13,14)$.

Nutraceuticals can be defined as a food or part of a food that provides medical or health benefits, including the prevention and/or treatment of diseases (15). They are found in a number of products from food industry, herbal supplements, dietary supplements and pharmaceutical industries (16). Nutraceuticals are used in most therapeutic areas that include disorders related to sleep, digestion, cold and cough, prevention of cancer, blood pressure, pain killers, depression, obesity, hyperglycemia and hypoglycemia (17). Considering the role of oxidative stress in the pathogenesis of many diseases, development of antioxidants rich nutraceutical will provide a better treatment strategy with fewer side effects in such patients. The present study involved the formulation and nutritional analysis of a nutraceutical with antioxidant activity. 


\section{Materials and Methods}

Chemicals/Reagents: All Chemicals and reagent used for this study were of analytical grade. Metaphosphoric acid , thiourea, 2,4-Dinitrophenylhydrazine (DNPH), potassium hydroxide and xylene were purchased from Sigma-Aldirich, UK. Per chloric acid, $\alpha \alpha$ - dipyridyl, nitric acid (HNO) and sodium 3 hydroxide were purchased from Fisher Scientific, USA.

\section{Ingredients for Nutraceutical Preparation}

Fresh onion, tomato, garlic, ginger, lemon, water melon and palm oil were purchased from Ramin Kura market Sokoto, Sokoto State, Nigeria. The samples were identified by Mal. A. A.Umar, a taxonomist in the Herbarium, Botany unit, Department of Biological Sciences, Usmanu Danfodiyo University Sokoto, voucher specimen was dropped at the Herbarium. The samples were taken to the laboratory immediately for formulation of the nutraceutical.

\section{Formulation of the Nutraceutical}

Tomatoes, Ginger, Onion, Garlic, Water melon seed, Lemon juice and Palm oil were used in the preparation in ratio of $2: 2: 2: 2: 1: 0.5: 0.5$ respectively. Water melon seeds were collected by dissecting water melon with a knife, the seeds were then pounded using mortar and pestle, ten grams of the pounded seed material and twenty grams each of sliced and pounded fresh tomatoes, ginger, Onion and garlic were placed in a beaker. The content were emptied into a blender, one hundred millilitre $(\mathrm{ml})$ of distilled deionized water was added and blended for two minutes. The content was then transferred into a conical flask. Lemon juice and palm oil (five grams each) were measured and added in to the conical flask respectively. The content was mixed thoroughly; after which the conical flask was covered with aluminium foil. The sample was then stored in a refrigerator at four degrees Celsius $\left(4^{\circ} \mathrm{C}\right)$ for further analysis.

\section{Proximate Composition of the Nutraceutical}

For the determination of moisture, ash, crude lipid and crude fibre, method of the Association of Official Analytical Chemist (AOAC) (18) was used. For crude protein, AOAC (18) was also used. Available carbohydrates were estimated by subtracting the total percentages of crude protein, crude lipid, crude fibre and ash content from $100 \%$ moisture free sample (19).

\section{Analysis of Antioxidant Vitamins and Minerals}

Vitamin C was determined by the method of Rutkowski and Grzegorczyk (20). To $0.5 \mathrm{ml}$ of sample, $2 \mathrm{ml}$ of freshly prepared $6 \%$ metaphosphoric acid was added, mixed thoroughly and centrifuged for 10 minutes (10 mins) at three thousand five hundred revolutions per minute (3500 rpm). Similarly, blank andstandard were prepared but instead of sample, $0.5 \mathrm{ml}$ of distilled water and standard were added respectively. To $1.2 \mathrm{ml}$ of supernatant, $0.4 \mathrm{ml}$ of Dithiocarbamate (DTC) reagent $(5 \mathrm{ml}$ of $5 \%$ thiourea solution $+5 \mathrm{ml}$ of $0.6 \%$ copper sulphate
+ $10 \mathrm{ml}$ 2,4-Dinitrophenylhydrazine (DNPH) reagent) was added, mixed and incubated in a water bath at $37^{\circ} \mathrm{C}$ for 3 hours. The test tubes were transferred into ice bath for 10 mins. Two millilitres $(2 \mathrm{ml})$ of $12 \mathrm{M}$ sulphuric acid was added and mixed. The absorbance was read at five hundred and twenty nanometre (520 nm) after zeroing the instrument with blank. Concentration of vitamin $\mathrm{C}$ was calculated by dividing the absorbance of sample by the absorbance of standard, hen multiplying the result by concentration of standard.

Vitamin A was estimated by the method of Rutkowski et al., (21). One milliliter $(1 \mathrm{ml})$ each of the sample and potassium hydroxide $(\mathrm{KOH})$ solution were placed into a centrifugal test tube, then it was shaken vigorously for 1 $\min$. The tube was heated in a water bath $\left(60^{\circ} \mathrm{C}, 20\right.$ mins $)$, then cooled. One millilitre $(1 \mathrm{ml})$ of xylene was added and the test tube was shaken vigorously again for one min. The mixture was centrifuged for ten min at $4000 \mathrm{rpm}$, the supernatant was transferred to a glass test tube and the absorbance of the solution was read at $335 \mathrm{~nm}$ against xylene $\left(A_{1}\right)$. The xylene extract 1 was irradiated to UV light for 30 minutes, until a steady absorbance $\left(A_{2}\right)$ was obtained at $335 \mathrm{~nm}$. The absorbance of retinol was obtained by subtracting the second absorbance $\left(A_{2}\right)$ from the 2 initial absorbance $\left(A_{1}\right)$. The concentration $\left.C_{x}\right)$ of vitamin $A$ in the sample was calculated by multiplying 22.23 to the difference of $A_{2}$ from $A_{1}$. Where: 22.23 is the multiplier on basis of the absorption coefficient of $1 \%$ solution of vitamin A (as the retinol form) in xylene at $335 \mathrm{~nm}$ in a measuring cuvette of about thickness one centimetre.

Vitamin $\mathrm{E}$ was estimated by the method of Rutkowski et al., (22). To $1.5 \mathrm{ml}$ of sample, $1.5 \mathrm{ml}$ of ethanol and 2.0 $\mathrm{ml}$ of xylene were added and centrifuged (2500 rpm, 10 mins). Similarly, standard and blank test tubes were prepared by adding standard vitamin $\mathrm{E}$ and distilled water respectively instead of the sample. One millilitre of xylene layer was pipetted into another set of identically labeled test tubes and $1 \mathrm{ml}$ of $\alpha \alpha$-dipyridyl reagent was added to the test tubes, contents were mixed and the absorbance of sample and standard was read against blank at $460 \mathrm{~nm}$. After 3 minutes, $0.33 \mathrm{ml}$ of ferric chloride was added to the test tubes and another absorbance was taken at $520 \mathrm{~nm}$. Concentration of vitamin $\mathrm{E}$ was calculated by subtracting the absorbance of sample at $460 \mathrm{~nm}$ from the absorbance of sample at $520 \mathrm{~nm}$, multiplying the result by concentration of standard, then dividing the result by absorbance of standard at $520 \mathrm{~nm}$.

Atomic absorption spectrophotometry (AAS) (23) was used for the determination of Copper, Zinc, Chromium and Manganese. The sample was digested before mineral quantification by adding $5 \mathrm{mls}$ of concentrated nitric acid $(\mathrm{HNO})_{3}$ to $2 \mathrm{mls}$ of the sample in a beaker; the solution was heated on a hot plate until a clear solution was formed. Per chloric acid $(1 \mathrm{ml})$ was added and the content was further heated to a clear solution. Distilled deionised $\mathrm{H}_{2} \mathrm{O}$ was added to 2 make $10 \mathrm{mls}$ and the solution was then filtered. The volume was then made up to $50 \mathrm{mls}$ with distilled deionised $\mathrm{HO}$ using a clean volumetric 2 flask (24).

Fatty Acid Analysis: The fatty acids in the sample were determined by the method described by Lokonge et al., (25). The sample (50 mg) was dissolved in $1 \mathrm{dm}^{3}$ 
dry toluene in a test tube to which $2 \mathrm{~cm} 30.5 \mathrm{M}$ sodium hydroxide in methanol was added, and the solution was maintained at $50^{\circ} \mathrm{C}$ for 10 minutes. The required esters were extracted into $5 \mathrm{~cm} 3$ hexane twice using a Pasteur pipette to separate the layers. The extract was dried over anhydrous sodium sulphate and filtered; and the solvent was later evaporated at low temperature. The fatty acid methyl esters generated were used for GCMS analysis.

Amino acid Profiles: The Amino acid profile of the sample was determined as described by Benitez, (26). The sample was dried to constant weight, defatted, hydrolysed, evaporated in a rotary evaporator and load ed into the Applied Bio systems PTH Amino Acid Analyser (Technicon Sequential Multiple Amino Acid Analyser, Dublin, UK).

Statistical Analysis: All data are presented as mean \pm SEM. SPSS version 20 was used for the analysis of data.

\section{RESULTS}

The result obtained in this study revealed the proximate composition, antioxidant vitamins and minerals, fatty acids and amino acids content in the formulated nutraceutical. The result of the proximate composition of the nutraceutical is presented in Table 1 . The result revealed that the nutraceutical is rich in proteins, lipids and carbohydrate, while the moisture and crude fibre content were low. The antioxidant vitamins content is shown in Table 2. The amount of vitamin A (12.70 \pm 3.7 $\mathrm{mg} / 100 \mathrm{~g}$ ) present in the nutraceutical is highest compared to vitamins $C$ and $E$ though their levels are appreciable. The result of the antioxidant minerals composition of the nutraceutical is as presented in Table 3. Of all the minerals analysed ( $\mathrm{Mn}, \mathrm{Cr}, \mathrm{Cu}$ and $\mathrm{Zn}), \mathrm{Mn}$ is the most abundant $(590.10 \pm 4.4 \mathrm{mg} / 100 \mathrm{~g})$ while $\mathrm{Zn}$ and Cu were low. The fatty acids detected in the nutraceutical are presented in Table 4 and include Oleic, Lauric, Stearic acids. However, no essential fatty acids (Linoleic and Linolenic acids) were detected in the nutraceutical. Amino acid profiles of the nutraceutical indicated the presence of essential and non essential amino acids (Table 5).

Table 1: Proximate Composition of the Formulated Nutraceutical

\begin{tabular}{lc}
\hline COMPOSITION & $\%$ COMPOSITION \\
\hline Moisture & $4.00 \pm 0.02$ \\
Ash & $3.00 \pm 0.001$ \\
Lipid & $30.00 \pm 0.06$ \\
Protein & $22.09 \pm 0.01$ \\
Fibre & $2.12 \pm 0.07$ \\
Carbohydrates & $38.78 \pm 0.05$ \\
\hline Results are expressed as mean \pm standard error of mean.
\end{tabular}

\section{Discussion}

The proximate composition of the formulated nutraceutical in the present study revealed the presence of moisture, ash, carbohydrate, protein, crude fibre, and lipids. The moisture content of the nutraceutical was
Table 2: Antioxidant Vitamins Content of the Formulated Nutraceutical

\begin{tabular}{lc}
\hline Antioxidant vitamins & Concentration $(\mathbf{m g} / \mathbf{1 0 0 g})$ \\
\hline Vitamin A & $12.70 \pm 3.7$ \\
Vitamin C & $8.20 \pm 0.04$ \\
Vitamin E & $5.40 \pm 0.04$ \\
\hline
\end{tabular}

Results are expressed as mean \pm standard error of mean.

Table 3: Antioxidant Minerals Content of the Formulated Nutraceutical

\begin{tabular}{lc}
\hline Antioxidant minerals & Concentration $(\mathbf{m g} / \mathbf{1 0 0 g})$ \\
\hline Manganese & $590.10 \pm 4.4$ \\
Zinc & $5.20 \pm 0.2$ \\
Copper & $5.30 \pm 7.3$ \\
Chromium & $212.20 \pm 16.6$ \\
\hline
\end{tabular}

Results are expressed as mean \pm standard error of mean.

Table 4: Fatty acids Content of the Formulated Nutraceutical

\begin{tabular}{lc}
\hline Fatty acid & Observation \\
\hline Lauric acid & +++ \\
Oleic acid & +++ \\
Stearic acid & ++ \\
Linoleic acid & - \\
Linolenic acid & - \\
\hline
\end{tabular}

KEY: + Abundant, ++; More abundant, +++; Most abundant, -;Not detected.

Table 5: Amino acids Content of the Formulated Nutraceutical

\begin{tabular}{lc}
\hline Amino acid & $\begin{array}{c}\text { Concentration } \\
\text { (mg/100g) }\end{array}$ \\
\hline Leucine & 1365.16 \\
Lysine & 689.20 \\
Isoleucine & 709.09 \\
Phenylalanine & 1252.50 \\
Valine & 793.03 \\
Methionine & 293.80 \\
Arginine & 1614.78 \\
Histidine & 627.36 \\
Threonine & 881.39 \\
Proline & 852.67 \\
Tyrosine & 682.58 \\
Cysteine & 293.80 \\
Alanine & 804.08 \\
Glutamic acid & 2909.00 \\
Glycine & 976.38 \\
Serine & 821.75 \\
Aspartic acid & 1875.44 \\
\hline
\end{tabular}

Results are expressed as mean \pm standard error of mean.

found to be low which suggests relatively long shelf life of the nutraceutical since high moisture content of food materials has been reported to be associated with increased growth of microorganisms (27) and consequently spoilage of food materials. Ash is an indication of the micronutrient content of food materials (28). The high amount of ash in the nutraceutical indicates high amount of minerals and this may be one of the reasons for it to have pharmacological effect.

The considerable amount of protein that was detected in the formulated nutraceutical suggest that it can reduce the risk of cardiovascular diseases since protein lowers plasma triglycerides (29), and reduces LDL, VLDL 
and cholesterol levels (30), The significant amount of protein contents of the nutraceutical could have supplementary effect for daily protein requirement. The low carbohydrate content of the nutraceutical will make it suitable for metabolic syndrome patients as carbohydrate restriction is part of recommended strategy in metabolic syndrome management because high carbohydrate intake increases the requirement for insulin secretion in order to maintain glucose homeostasis (31).

The dietary fibre content of the newly developed nutraceutical was not high but can be improved because dietary fibre is one of the factors that influence the post prandial glucose and insulin tolerance (32). Cross sectional studies have shown that lack of fibre may be a causative factor of type 2 diabetes and have also shown an inverse relationship with insulin level $(33,34)$. Chandalia et al. (35) reported that high fibre supplements could improve glucose tolerance. In addition, the nutritional implications of fibre are to prevent diverticulosis and aid absorption of trace elements in the gut as well as elimination of undigested food material through the bowel $(36,37)$ and to prevent certain form of cancer (38) so necessitating the need to improve the dietary fibre content of the formulated nutraceutical. The formulated nutraceutical was found to be rich in lipids and since lipids from vegetable sources have been reported to lower the risk of type 2 diabetes mellitus (T2DM) (39) and cardiovascular diseases (40), for energy source, transport of fat soluble vitamins and also for insulation and protection of internal tissues, it can have advantageous effect on various diseases.

The concentration of vitamin A in the nutraceutical is appreciable. It has been reported that onion, garlic and ginger are good sources of vitamin A (41) and could be the reason for high amount of vitamin $A$ in the nutraceutical. The value obtained is higher than that obtained in white ginger $(8.4 \pm 0.0 \mathrm{mg} / 100 \mathrm{ml})$ and garlic $(13.4 \pm 0.0 \mathrm{mg} / 100 \mathrm{ml})(42)$. Vitamin A supplementation has been reported to lower systolic blood pressure in salt induced hypertensive rats, it also lowers LDL oxidation and improves endothelial function in metabolic syndrome (43). Being an antioxidant, vitamin A can play significant roles in the management of CVDs and obesity through scavenging of free radicals.

The amount of Vitamin $C$ in the formulated nutraceutical is appreciable; the presence of which may be due to the presence of tomato, ginger, lemon, watermelon seed and garlic. However, this is lower than the vitamin C level in garlic and onion (18.0 mg/100 ml) (44), and lemon $(53.0 \mathrm{mg} / 100 \mathrm{ml})$ reported by Bilbis et al., (43). However the value is higher than the one obtained from fresh watermelon seed (45). Vitamin C supplementation in T2DM improved blood glucose level (46) which is a component of metabolic syndrome. Vitamin $\mathrm{C}$ is known for its antioxidative activity thus can protect the body against the development of diseases caused by oxidative stress such as cancer, Parkinson's disease, Alzheimer's disease, myocardial infarction and Sickle Cell Disease.

The amount of vitamin $E$ in the nutraceutical is also appreciable and is likely attributable to the presence of ginger and onion. The value is higher than (3.6 \pm 0.0 $\mathrm{mg} / 100 \mathrm{ml})$ and $(1.6 \pm 0.00 \mathrm{mg} / 100 \mathrm{ml})$ those obtained from white ginger and onion respectively (47). This may likely be due to the different variety of constituents used in the preparation of the nutraceutical. The significant level of vitamin $E$ in the nutraceutical could play a vital role in the antioxidant defence system. It has been reported that increased dietary level of vitamin E results in higher tissue á-tocopherol concentration and greater stability toward lipid peroxidation (48).

The antioxidant vitamins $A, C$ and $E$ play a significant role as antihypertensive agents (47), help in the management of diabetes mellitus (49) as well as other complications that are components of metabolic syndrome probably due to their roles in scavenging free radicals. The antioxidant minerals ( $\mathrm{Mn}, \mathrm{Cr}, \mathrm{Cu}$ and $\mathrm{Zn}$ ) were also detected, the result indicates that the minerals increase in the order $\mathrm{Mn}>\mathrm{Cr}>\mathrm{Cu}>\mathrm{Zn}$. Antioxidant minerals important roles in maintaining immune function and neutralizing the reactive oxygen intermediates produced by activated macrophages and neutrophils and act as cofactors for antioxidant enzymes (50). Mn has been reported to play a significant role in insulin synthesis and secretion (51). Type II diabetic subjects also respond well to oral doses of $\mathrm{Mn}$ (49). $\mathrm{Mn}$ is a cofactor of many enzymes including mitochondrial superoxide dismutase (52), it activates enzymes that play important roles in the metabolism of carbohydrates, amino acids and cholesterol. $\mathrm{Cr}$ has been known to be a component of glucose tolerance factor required for optimal glucose utilization by cells (53), increase insulin binding to cells and triggers insulin receptor kinase leading to increase insulin sensitivity (49). The concentration of Copper and Zinc are lower than those of Mn and $\mathrm{Cr}$ in the nutraceutical. $\mathrm{Cu}$ and $\mathrm{Zn}$ are components of superoxide dismutase which are responsible for mopping up free radicals (54) hence prevent oxidative stress which is associated with metabolic syndrome. Apart from having antioxidative properties, they also play other vital roles such as regulation of cellular growth and participate as co-factors of enzymes responsible for carbohydrate, proteins and nucleic acid metabolism in the system (55). Low level of the minerals has also been reported to correlate with the activity of antioxidant enzymes (56). Thus, the appreciable amount of the antioxidant minerals in the nutraceutical could help in the management of metabolic syndrome by increasing the activity of antioxidant enzymes.

Although many fatty acids were detected in the formulated nutraceutical, no essential fatty acid was detected. Free fatty acids have roles in host defence against potential opportunistic or pathogenic microorganisms (57). Indeed, fatty acids are normally identified as active ingredients in ethnic and herbal medicines (58), free fatty acids also serve as a source of energy and play pivotal roles in the body (59).

Amino acid profile revealed that all the essential and non-essential amino acids were detected in the formulated nutraceutical. The essential amino acids most importantly, have to be provided in the diet due to inability of synthesis by humans (60). Presence of appreciable amount of essential amino acids in the 
nutraceutical could be a good source of nutrient for patients having diseases related to oxidative stress. Arginine and Leucine have the highest concentration among the essential amino acids. It has been reported that Arginine plays important roles in weight loss (61), antihypertensive (62), management of obesity and type 2 diabetes (63). Leucine helps in lowering LDL and cholesterol (64). These properties of essential amino acids could help in the management of metabolic syndrome.

Among the non-essential amino acids, glutamic acid $(2909.25 \mathrm{mg} / 100 \mathrm{~g})$ and aspartic acid $(1875.44$ $\mathrm{mg} / 100 \mathrm{~g}$ ) were found to have the highest concentration. Glutamic acid has anticancer effect (65) while aspartic acid has immune function, increase resistance to fatigue and energy production (66). The considerable amount of amino acids (essential and nonessential) of the formulated nutraceutical can serve as good source of amino acids for protein synthesis and other physiological roles (67).

Conclusion: The presence of appreciable amount of antioxidant vitamins and minerals, essential and nonessential amino acids as well as macronutrients in the formulated nutraceutical could serve as a good source of these nutrients which can play significant roles in health maintenance and contribute to reducing the risk of CVDS and other degenerative diseases associated with free radical damage.

\section{References}

1. Ginter E., Simko V., Panakova V. Antioxidants in health and disease. Bratislava Medical Journal. 2014; 115:603-606.

2. Beckman K.B., Ames B.N. Endogenous oxidative damage of mtDNA. Mutation Research. 1999; 424:51-58.

3. Wei Y.H., Lu C.Y., Wei C.Y., Ma Y.S., Lee H.C. Oxidative stress in human aging and mitochondrial disease consequences of defective mitochondrial respiration and impaired antioxidant enzyme system. Chinese Journal of Physiology. 2001; 44:1-11.

4. Linke A., Adams V., Schulze P.C., Erbs S., Gielen S. Antioxidative effects of exercise training in patients with chronic heart failure: Increase in radical scavenger enzyme activity in skeletal muscle. Circulation. 2005; 111:1763-1770.

5. Cristina P.M., Pratico D., Savino K., Rokach J., Stahl W., Mecocci $\mathrm{P}$. Increased F2 iso- prostane plasma levels in patients with con gestive heart failure are correlated with antioxidant status and disease severity. Journal of Cardiac Failure. 2004; 10:334-338.

6. De Champlain J., Wu R., Girouard H. Oxidative stress in hyper tension. Clinical and Experimental Hypertension. 2004; 26:593-601.

7. John W.B., Suzanne R.T. Role of oxidative stress in diabetic com plications. Diabetes. 1999; 48:1-9.

8. Van Gaal L.F., Vertommen J., De Leeuw I.H. The in vitro oxidiza bility of lipoprotein particles in obese and non-obese subjects. Atherosclerosis. 1998; 137:S39-S44.

9. Taibur R., Ismail H., Towhidul Islam M.M., Hossainuddin S. Oxida tive stress and Health. Advances in Bioscience and Biotechnology. 2012; 3:997-1019.

10.Miyajima K., Minatoguchi S., Ito Y. Reduction of QTc dispersion by the angiotensin II receptor blocker valsartan may be related to its anti-oxidative stress effect in patients with essential hypertension. Hypertension Research. 2007; 30(4):307-313.

11.Pooja P., Sushil K.J., Subhashini Y. Metabolic syndrome and cancer. Metabolic Syndrome and Related Disorders. 2009: 7(4):279-287.

12.Firuzi O., Miri R., Tavakkoli M., Saso L. Antioxidant therapy: cur rent status and future prospects. Curr Med Chem. 2011; 18(25): 3871-3888.

13.Lobo V., Patil A., Phatak A., Chandra N. Free radicals, antioxidants and functional foods: impact on human health. Pharmacogn Rev. 2010; 4(8):118-126.
14. Ferroni P., Della-Morte D., Palmirotta R. Platinum-based comp ounds and risk for cardiovascular toxicity in the elderly: role of the antioxidants in chemoprevention. Rejuvenation Res. 2011; 14(3): 293-308.

15. Elizabeth A.C. Over the counter products: nonprescription medi cations, nutraceuticals, and herbal agents. Clinical Obstetrics and Gynecology. 2002; 45(1):89-98.

16. Kaur G., Mukundan S., Vaidehi W., Maushmi S.K. Nutraceutical in the management of metabolic syndrome. Austin Journal of Pharmacology and Therapeutics. 2015; 3(1):1-6.

17. John S., Schmieder R. Potential mechanisms of impaired endoth elial function in arterial hypertension and hypercholesterolemia. Current Hypertension Reports. 2003; 5(3):199-207.

18. AOAC (Association of Official Analytical Chemists) (2000). Official Methods of Analysis of the AOAC (W. Horwitz Editor Eighteen Editions, Washington D.C., AOAC).

19. Hunt C., Burn P., Ademezul Z.C. Proximate composition and fat content of different types of the popular take away meals. Inter national Journal of Food Science and Technology. 1987; 22:669 -759 .

20. Rutkowski M., Grzegorczyk K. Colorimetric determination of vita min C concentration in blood plasma with Dithiocarbamate rea gent, a modification of Kyaw method. Diagnostic Laboratory. 1998;34:243.

21. Rutkowski M., Grzegorczyk K., Gendek E., Kêdziora J. Laboratory convenient modification of Bessey method for vitamin A deter mination in blood plasma. Journal of Physiology and Pharmaco logy. 2006;57:221.

22. Rutkowski M., Grzegorczyk K., Paradowski M.T. Colorimetric method of blood plasma total vitamin E determination. Diagnostic Laboratory. 2005;41:375

23. Bhatti M., Peter S.J., John E. Determination of trace elements using Unicam 969 Atomic absorption Spectrophotometer. Annal International Medicine. 2006;205(1):96-105.

24. Walinga I., Vark W.V., Lee J..V.D. Soil and plant analysis, part 7: plant analysis procedure. A series syllabi, wageningen Agricultural University, Netherlands. 1989;10-16.

25. Lokonge E., Labuschagne M.T., Hugo A. The evaluation of oil and fatty acids composition in seed of cotton accessions from various Countries. Journal of the Science of Food and Agriculture. 2007; 87:340-347

26. Benitez L.V. Amino Acid and fatty acid profiles in aquaculture nutrition studies, Fish Nutrition Research in Asia. in S.S. De Silva ed. Manila Philippines; 1989;235.

27. Kyoung-Hee C., Heeyoung L., Soomin L., Sejeong K., Yohan Y. Cheese microbial risk assessment: A review. Asian-Australian Journal of Animal Science. 2016;29(3):307-314.

28. Vanhanen L., Emmertz A., Savage G. Mineral analysis of mono floral New Zealand honey. Food Chemistry. 2011;128:236-240.

29. Kawamoto R., Tabar Y., Kohar k., Miki T., Kusunoki T., Abe M., Katoh T., Ohtsuka N. Relationship between lipid profiles and metabolic syndrome, insulin resistance and serum high molecular adiponectin in Japanese community-dwelling Adults. Lipid in health and disease. 2011;10: 79 .

30. Ann B., Kjeld H. Effect of dairy protein and fat on metabolic syn drome and type 2 diabetes. Review of Diabetic Studies. 2014; 11(2):153-166.

31. Reaven G.M. The metabolic syndrome: Is this diagnosis necessary? American Journal of Clinical Nutrition. 2006;83:1237-1247.

32. Granfeldt Y., Hagander B., Bjorck I. Metabolic responses to starch in oat and wheat products: On the importance of food structure, incomplete gelatinization or presence of viscous fibre. European Journal of Clinical Nutrition. 1995;49:189-99.

33. Trowell H.C. Dietary fibre hypothesis of the aetiology of diabetes mellitus. Diabetes. 1975; 24:762-5.

34. Lovejoy J., DiGirolamo M. Habitual dietary intake and insulin sensitivity in lean and obese adults. American Journal of Clinical Nutrition. 1992; 55:1174-1179.

35. Chandalia M., Garg A., Luthohann D., Von Bergman K., Grundy S.M., Brinkley L.J. Beneficial effects of a high dietary fiber intake in patients with type 2 diabetes mellitus. The New England Jour nal of Medicine. 2002;342:1392-1398.

36. Bilbis L.S., Muhammad S.A., Saidu Y. (2014). The Potentials of Antioxidant Micronutrients in The Management of Metabolic syn drome. Journal of Antioxidant Activity. 2014;1(1):1-21. 
37. Vasudevan P., Muthusami J. Assessing the Nutraceutical Signifi cance of the medicinal herb ammannia baccifera $L$. by proximate, mineral analysis and phytochemical screening. World journal of pharmaceutical medical research. 2016;2(5):65-71.

38. Baghurst P.A., Rohan T.E. High-fiber diets and reduced risk of breast cancer. International Journal of Cancer. 1994;15(2):173176.

39. Salmeron J., Manson J.E., Stampfer M.J., Colditz G.A., Wing A.L., Willett W.C. Dietary fiber, glycemic load, and risk of non-insulin dependent diabetes mellitus in women. Journal of the American Medical Association. 1997;277:472-7.

40. Adebawo O., Salau B., Ezima E., Oyefuga O.L., Ajani E., Idowu G., Fmodu A., Osilesi O. Fruits and vegetable moderate lipid cardiovascular risk factor in hypertensive patients. Lipids health Disease. 2006;5:14.

41. Ock K.C., Melissa A., Moser A. Vitamin C and Heart Health: A Review Based on Findings from Epidemiologic Studies. Interna tional Journal of Molecular Science. 2016;17:1328-1335.

42. Kanza A., Masood S.B., Lahtisham U.H., Hafiz S. Investigating the Antioxidant Potential of Garlic (Allium Sativum) Extracts through Different Extraction Modes. Current Bioactive Compounds. 2017; 13(1):43-50.

43. Bilbis L.S.., Muhammad S.A., Saidu Y., Adamu Y. Effect of Vitamin A, C and E Supplementation in the Treatment of Metabolic syn drome in Albino Rats. Biochemistry Research International. 2012; 678-682.

44. Akinwande B.A., Olafinde S.J. Comparative evaluation of the mineral profile and other selected compounds of onion and garlic. International Food Research Journal. 2015;22(1):332-336.

45. Jhonson J.T., Lennox J.A., Ujong U.P., Odey M.O., Fila W.O., Edem P.N., Dasofunjo K. Comparative Vitamins Content of Pulp Seed and Rind of Fresh and Dried Water melon. International Journal of Science and Technology. 2013;2(1):99-103.

46. Ganesh N., Dakhale H., Chaudhari V., Meena S. Supplementation of Vitamin C Reduces Blood Glucose and Improves Glycosylated Haemoglobin in Type 2 Diabetes Mellitus: A Randomized, DoubleBlinded Study. Advances in Pharmacological Sciences. 2011;1-5.

47. Olubunmi B.A., Seun F.A, Funmilayo, T.A. Food Value of Two Varieties of Ginger (Zingiber Officinale) Commonly Consumed in Nigeria. International Scholarly Research Notices. 2013;5:39-44.

48. Dhawan V., Jain S. Garlic supplementation prevents oxidative DNA Damage in essential hypertension. PubMed. 2005;275(1-2):85-9.

49. Davi G., Santilli F., Patrono C. Nutraceuticals in Diabetes and Metabolic Syndrome, Cardiovascular Therapeutics. 2015;28(2010): 216-226.

50. Roberts K.M., Daryl K.G., Peter A.M., Victor W.K. Harper's Biochemistry, 25th ed. Lange Medical Book: Appleton and Lange. 2000;209-210.

51. Praveeena S., Sujatha P., Sameera K. Trace element in diabetes mellitus, Journal of Clinical and Diagnostic Research. 2013;7(9): 1863-1865.

52. Sironi A.M, Gastaldelli A., Mari A. Visceral fat in hypertension:
Influence on insulin resistance and beta-cell function. Journal of Hypertension. 2004;44:127-133.

53. Khan V., Najmi A.K., Akhtar M., Aqil M., Mujeeb M., Pillai K.K. A pharmacological appraisal of medicinal plants with antidiabetic potential. Journal of Pharmaceutical Bioallied Science. 2012; 4:27-42.

54. Shills M.E.G. Modern Nutrition in Health and Diseases, Lippincott: Philadelphis: Williams and Wilkins. 2005;180-193.

55. Wuerges J., Lee J.W., Yim Y.I., Yim H.S., Kang S.O., Djinovic C.K. Crystal structure of nickel-containing superoxide dismutase reveals another type of active site. Proceedings National Academic of Science USA. 2004;101:8569-74.

56. WHO. (1996). Trace elements in human nutrition and health, Geneva: World Health Organization: 186.

57. Marreiro D.N., Vanessa B.L., Fabiane A.S., Daila L., Chaves B. Machado M.N. Parameters of glycemic control and their relation ship with zinc concentrations in blood and with superoxide dis mutase enzyme activity in type 2 diabetes patients. Archive of Endocrinology and Metabolism. 2011;55:9-16

58. Geman, J. Food processing and lipid oxidation. Advances in Experimental Medicine and Biology. 1999;459:23-50.

59. Jana O., Ladislava M., Jarmila V.A., Robert V., Jiri Mlcek. Fatty acids composition of vegetable and its contribution to dietary energy intake and dependence of cardiovascular mortality on dietary intake of fatty acids. International Journal of Molecular Sciences. 2015;16(6):12871-12890.

60. Elena V., Hisamine K., Melinda S., Bettina M., Robert W. Essential Amino Acids are primarily responsible for the Amino Acid Stimu lation Of muscle protein anabolism in healthy elderly adults. American Journal of Clinical Nutrition. 2003;78(2):250-258.

61. Jillon S., Wal V., Marth J.M. Short-term effect of eggs on satiety in overweight and obese subjects. J Am Coll Nutr. 2005;24:510-5.

62. McGaw L.J., Jager A.K., Van Staden J. Antibacterial effects of fatty acids and related compounds from plants. South African Journal of Botany. 2002;68:417-23.

63. Azadbakht L., Atabak S. Soy protein intake, cardio renal indices, and $\mathrm{C}$ - reactive protein in type 2 diabetes with nephro-pathy. Diabetes Care. 2008;31 (4):648-54.

64. Suhad S., AbuMweis R.B., Roula B., Peter J.J.H. Plant sterols/ stanol as cholesterol lowering agent: A meta-analysis of random ised control trials. Journal of Food and Nutrition Research. 2008; 52:10.

65. Ismail E.H, Abdel-Mageed A.I., Mohamed H., Khalil M.M.H. In vitro anticancer and biological activity studies for new synthesized transition metal ternary complexes. International Journal of Sci ence and Research. 2015;4:107-12.

66. Topo E., Soricelli A., DAniello A., Ronsini S., DAniello G. The role and molecular mechanism of $\mathrm{D}$-aspartic acid in the release and synthesis of $\mathrm{LH}$ and testosterone in humans and rats. Repro ductive Biology and Endocrinology 2009; 27-39.

67. Berg J.M., Tymoczko J.L., Stryer L. Biochemistry. ${ }^{5} \mathrm{n}$ ed. New York: W H Freeman. 2002; 12-15. 